\title{
APRENDIZAGEM BASEADA EM PROBLEMAS E MAPA CONCEITUAL: UMA EXPERIÊNCIA COM ALUNOS DO CURSO DE PEDAGOGIA
}

\author{
Francisca Melo Agapito ${ }^{1}$ \\ Andreia Aparecida Guimarães Strohschoen ${ }^{2}$
}

\begin{abstract}
Resumo: O presente artigo tem como objetivo relatar a percepção de alunos sobre utilização das estratégias pedagógicas denominadas: mapa conceitual e aprendizagem baseada em problemas como potencializadoras do processo de aprendizagem do conteúdo "Políticas públicas para pessoas com deficiência", no curso de Pedagogia de uma instituiçấo de Ensino Superior no município de Imperatriz-MA. O estudo configura-se como uma pesquisa-ação, com abordagem qualitativa e pautada na análise descritiva. A utilização destes mecanismos possibilitou a melhoria da qualidade das aulas, tornando-as mais atrativas, além de motivar os alunos para o aprendizado do conteúdo proposto através de uma atividade diferente. As estratégias foram extremamente satisfatórias, propiciando o engajamento dos alunos para a realização das mesmas, além de trazer uma nova percepção acerca da construção de conhecimentos e da diversidade de atividades que são possíveis para efetivar a aprendizagem. Nesta perspectiva, essa experiência contribuiu para uma construçâo significativa, bem como, para tornar as aulas inovadoras para os alunos, proporcionando assim, uma melhor aprendizagem que embasará futuras tomadas de decisão na vida profissional.
\end{abstract}

Palavras-chave: Aprendizagem. Aulas inovadoras. Mediação pedagógica. Construção significativa. Estratégias de ensino.

\begin{abstract}
This article aims to report the perception of students on use of concept map strategies and problem-based learning as potentiating the content of the learning process "Public policies for people with disabilities" in the Faculty of Education of an education institution Superior in Imperatriz-MA. The study is an action research, with a qualitative approach based on the descriptive analysis. The use of these mechanisms allowed the improvement of the quality of the classes, making them more attractive, and motivate students to learn the content proposed by a different activity. Strategies were extremely satisfactory, providing the engagement of students for meeting them, and bring a new
\end{abstract}

1 Pedagoga. Especialista em Metodologia do Ensino Superior (UEMA) e Libras. Mestra em Ensino pelo Centro Universitário UNIVATES. Professora do PARFOR. Professora da Universidade Federal do Maranhão-UFMA.

2 Doutora em Ciências, ênfase em Ecologia pela UFRGS. Docente do Mestrado Profissional em Ensino de Ciências Exatas e Mestrado em Ensino da UNIVATES. 
perception about the construction of knowledge and the diversity of activities that are possible to effect learning. In this perspective, this experience contributed to a significant construction and to make innovative classes for students, thus providing a better learning to base future decision-making in working life.

Keywords: Learning. Innovative lessons. Pedagogical mediation. Significant construction. Teaching strategies.

\section{INTRODUÇÃO}

O processo de aprendizagem de cada indivíduo ocorre através de um construto integrado, ou seja, intelectual, afetivo e muscular, além de ocorrer de modo qualitativo, de acordo com cada indivíduo e suas peculiaridades (BORDENAVE, 2000). Ainda nesse sentido, a aprendizagem é definida conforme Gil (2012, p. 80) como um "processo de aquisição de conhecimentos, desenvolvimento de habilidades e mudança de atitudes em decorrência de experiências educativas, tais como aulas, leituras, discussões, pesquisas etc.". Por isso, as experiências educacionais vivenciadas pelos alunos podem efetivar a construção de conhecimentos, pois a aquisição destes é um processo que envolve de modo subjetivo as percepções de quem está imerso nessa construção.

O uso de estratégias de ensino que vislumbrem uma melhor aprendizagem por parte dos alunos torna-se extremamente relevante, na medida em que podem contemplar as diversas formas que cada um apreende os conhecimentos (ANASTASIOU; ALVES, 2012). Partindo desse pressuposto, percebe-se a importância de reconhecer e utilizar estratégias de ensino como propulsores que motivam, instigam e possibilitam construções significativas, além de propiciar diversidade e respeito no processo de aprendizagem.

Ademais, o professor tem o papel salutar de buscar meios para mediar o educando na apropriação de uma mentalidade científica, na capacidade de refletir, analisar, avaliar e criar, ou seja, preparar este para a vida em sociedade, (GIL, 2012). Nessa conjuntura, este ator social deve ter embasamento acerca de estratégias que potencializem as aprendizagens dos alunos, sendo essencial para mediar a aquisição de conhecimento pelos educandos.

O presente artigo relata reflexões decorrentes de uma experiência realizada com duas estratégias de ensino: mapa conceitual (MC) e aprendizagem baseada em problemas (ABP) como ferramentas relevantes para o processo de aprendizagem. O trabalho foi desenvolvido com acadêmicos do curso de pedagogia na disciplina de Educação Especial, em uma instituição de ensino superior (IES) de ImperatrizMA, e objetiva relatar a percepção de alunos sobre a utilização das estratégias supracitadas, expondo suas percepções frente a esta experiência e às possibilidades de aprendizagem e construção de conhecimentos vivenciadas. 


\section{FORMAÇÃO DOCENTE: SABERES NECESSÁRIOS}

A formação docente na atualidade deve vislumbrar a construção de uma identidade profissional, que contemple o planejamento, as teorias, as atividades práticas e um currículo que possibilite a construção da autonomia e da inovação. Nesse sentido, o eixo dessa formação é o trabalho pedagógico compreendido como ato educativo intencional que desenvolve competências e habilidades. Além de considerar também o desenvolvimento da criatividade, da intencionalidade e da autonomia, baseadas em conteúdos que levam à reflexão. Como afirma Nóvoa (1992, p. 25):

A formação não se constrói por acumulação de cursos, conhecimentos ou de técnicas, mas sim através de um trabalho de flexibilidade crítica sobre as práticas e de reconstrução permanente de uma identidade pessoal. Por isso é tão importante investir na formação pessoal, pois a mesma dar um estatuto ao saber da experiência.

Observa-se como importante considerar a questão da formação do professor não como uma questão apenas científica, nem meramente acadêmica, mas, sobretudo, como uma questão social e política. Isto implica levar em consideração a estrutura social e o momento histórico, uma vez que o desenvolvimento da identidade do indivíduo é determinado pelas condições históricas, sociais, materiais, sendo inclusas também as condições do próprio sujeito (ANASTASIOU; ALVES, 2012).

Neste contexto, vemos que a importância da formação de professores deve estar fundamentada de modo consistente, com um currículo que contemple as necessidades da função, para que estes tenham subsídios para ampliar suas concepções. Além de gerar uma postura ética, crítica e reflexiva para o desenvolvimento das atividades laborais nas relações que se estabelecerão na escola (NOGARO; DALMINA, 2014).

Entretanto, essa situação não é uma constante nos cursos de formação de professores, na maioria das vezes a teoria é mediada através de diversas disciplinas ao longo de muitos períodos na academia. E o currículo, desta forma, não possibilita a construção de conhecimentos práticos, não havendo o suporte necessário para adquirir referenciais práticos a fim de adentrar no mercado de trabalho (IMBERNÓN, 2006).

Outro fator que deve ser relevante para a formação profissional é o modo como o currículo organiza o trabalho docente para mediar as construções posteriores. Nesse sentido, torna-se imprescindível investir na formação de docentes, com vistas a capacitá-los para o exercício de sua função de forma consciente, reflexiva e crítica para realizar as mediações pertinentes. Para Sacristán (2000, p. 193):

A formação, a cultura geral do professor, a interação que nele se estabeleça entre o conhecimento de conteúdos e a diferenciação de aspectos relativos à sua estrutura com outros conhecimentos e valorizações pedagógicas serão as responsáveis pelo papel real de mediação que o professor tem no currículo. 
Desta forma, a formação do professor necessita ser permeada de situações teóricas e práticas que permitam o embasamento para o trabalho pedagógico. O currículo apresenta-se como extremamente importante para constituir-se como base para esse futuro profissional, vislumbrando além de uma construção cultural também uma participação social e ativa do docente no processo educativo que estará imerso.

O exercício da função docente requer competências oriundas da formação acadêmica. Nesse sentido, professores necessitam organizar ações voltadas para a construção de conhecimentos que propiciem práxis para uma futura atuação profissional de seus educandos. Ações que proporcionem a qualificação docente ao longo da oferta do currículo são fundamentais. Neste sentido, Tardif (2002), destaca que seria extremamente significativo que a formação de professores fosse baseada e se aprofundasse nos conhecimentos específicos da sua profissão.

Analisando o foco do ensino superior na abordagem de Severino (2007), identifica-se alguns objetivos considerados fundamentais para a formação profissional, dentre eles destaca-se: a formação crítica e cidadã que busque o estímulo para a tomada de decisões que contribuirão com a sociedade e a formação de profissionais das diversas áreas. Sobre esse aspecto Nogaro e Dalmina (2014, p. 13) esclarecem que a formação docente deve permitir "experimentar, corrigir, inovar, refletir sobre a sua ação enquanto ação colocar-se no lugar de aprendiz, lançar olhar crítico sobre sua prática e reconhecer quando é preciso mudar". Ou seja, uma formação que permita uma prática reflexiva.

Outro fator que merece destaque encontra-se nas experiências cotidianas na academia. A partir delas, ocorrem as construções de conhecimentos que servirão de base para futuras vivências em sala de aula, pois, as abstrações adquiridas ao longo desse processo são subjetivas e individuais e dependem de diversos fatores intrínsecos de cada indivíduo.

Sobre esse aspecto Saviani (2009) ressalta que o discente, ao estar imerso e aprender através das relações sociais vividas com tais conhecimentos, torna-se um agente que pode mediar a construção de novos conhecimentos quando estiver na posição de profissional da educação e que poderá proporcionar aos seus alunos uma gama de conhecimentos.

\section{ESTRATÉGIAS INOVADORAS DE ENSINO NA DISCIPLINA DE EDUCAÇÃO ESPECIAL: ALGUMAS CONSIDERAÇÓES}

As estratégias inovadoras de ensino podem ser instrumentos eficazes para potencializar a aprendizagem, proporcionando uma inovação nas aulas. Quando estas são introduzidas num momento oportuno, a possibilidade de aceitação será muito maior, propiciando ao professor trabalhar de forma otimizada e com vistas a mediar o processo de aprendizagem de modo significativo (BORDENAVE; PEREIRA, 2000). Estas estratégias, consideradas inovadoras, são pautadas por metodologias ativas de ensino e de aprendizagem, tendo como foco o estudante. 
Buscam uma visão relacional, com maior flexibilidade, mobilidade e complexidade para que as apropriações de conhecimento não sejam estáticas e sim dinâmicas, almejando a autonomia do estudante (ANASTASIOU; ALVES, 2012).

Além de tornar a apreensão dos conteúdos mais dinâmicos e atrativos, as estratégias inovadoras de ensino possibilitam construções eficazes pautadas nos objetivos propostos pelos professores que as utilizam como ferramentas nesse processo. Masetto (2003, p. 86) destaca o termo estratégia, conceituando-a como:

[...] arte de decidir sobre um conjunto de disposições, que favoreçam o alcance dos objetivos educacionais pelo aprendiz, desde a organização do espaço da sala de aula com suas carteiras até a preparação do material a ser usado, por exemplo, recursos audiovisuais, visitas técnicas, internet etc., ou uso de dinâmicas de grupo, ou outras atividades individuais.

Nesse sentido, o professor em sala de aula deve proporcionar ao aluno mecanismos inovadores que lhe possibilitem uma melhor apreensão dos conteúdos propostos, organizando-se de modo que a estratégia planejada almeje o alcance dos objetivos pretendidos previamente e concretize-se em um ato de aprendizagem e desenvolvimento do aluno na disciplina foco.

Nas palavras de Bordenave e Pereira (2008), as estratégias são meios para se facilitar da apreensão de conteúdos e faz-se necessário que docentes se envolvam no processo, buscando aquelas que são condizentes com o conteúdo e o objetivo proposto.

Consoante a isto, o professor tem a oportunidade de perceber o desenvolvimento de seus alunos e assim "[...] observar mais metodicamente os alunos" (PERRENOUD, 1999, p. 89), além de verificar como está ocorrendo o processo de aprendizagem ou os pontos que ainda merecem ser revistos. O referido autor acrescenta ainda que as estratégias podem permitir aos professores ajustar de modo mais específico as futuras intervenções pedagógicas.

Outro aspecto que merece enfoque encontra-se no ato do docente em realizar estratégias como canal para motivar os alunos a aprender determinado conteúdo, estimulando estes a obterem conhecimentos mais significativos para suas vivências. Além disso, utilizar diversas estratégias possibilita construções mentais que favorecem a apreensão de forma efetiva e muitas vezes mais rápida em comparação a uma aula tradicional (BORDENAVE; PEREIRA, 2000).

Pozo, Monereo e Castelló (2004, p. 154) afirmam ainda a relevância das estratégias estarem em consonância com determinado contexto em que se aplicam "em função das condições reais de aprendizagem, dos recursos disponíveis e das metas estabelecidas". Ressalta-se a indubitável relevância do conhecimento dos professores que fazem uso destas, para que o propósito de seu uso seja atingido de forma plena.

Adentrando no campo da disciplina de Educação Especial por fazer parte da matriz curricular dos cursos de formação de professores e exigir dos futuros docentes conhecimentos sobre uma gama de deficiências, torna-se relevante o 
estudo de subsídios teóricos e práticos para que os acadêmicos possam ter suporte para lidar com os conhecimentos necessários para a atuação com o público com deficiência.

A Política Nacional da Educação Especial na Perspectiva da Educação inclusiva (BRASIL, 2008) busca assegurar a inclusão escolar de alunos com deficiência, transtornos globais do desenvolvimento e altas habilidades/ superdotação. Isso significa dizer que são necessárias ações que possibilitem sua efetivação, dentre elas, a "formação de professores para o atendimento educacional especializado e demais profissionais da educação para a inclusão” (BRASIL, 2008).

Nesse panorama, a construção de conhecimentos por parte de futuros atores sociais que possivelmente estarão envolvidos no processo de aprendizagem de alunos com deficiência é essencial. O documento supracitado preconiza ainda que o processo de inclusão escolar deve se iniciar na educação infantil, proporcionando bases que busquem a construção do conhecimento e desenvolvimento global dos alunos com deficiência (IBID, 2008).

Ainda nesse sentido, destacam-se as Diretrizes Curriculares Nacionais para a Formação de Professores da Educação Básica, em nível superior, curso de licenciatura, de graduação plena, que em seu artigo $2^{\circ}$ prevê que a formação da atividade docente deve preparar o futuro profissional para "I - o ensino visando à aprendizagem do aluno; II - o acolhimento e o trato da diversidade" (BRASIL, 2002).

Tomando como base a premissa anterior, reforça-se o quanto é salutar que as Instituições de Ensino Superior (IES) e seus educadores no período de inserção da disciplina Educação Especial promovam efetivamente para seus educandos a aprendizagem de conteúdos voltados ao público com deficiência, tanto para construir uma formação coerente, quanto contribuir com as necessidades advindas de seu laboro futuro. Além disso, deve-se levar em consideração uma questão primordial, a formação para aqueles que desejam adentrar nessa área de estudo, uma vez que "Para atuar na educação especial, o professor deve ter como base de sua formação, inicial e continuada, conhecimentos gerais para o exercício da docência e conhecimentos específicos da área" (BRASIL, 2008, p. 17).

As estratégias de ensino, frente a essa realidade devem buscar oportunizar situações de aprendizagem, já que são várias as formas de se aprender por parte dos alunos e que há uma heterogeneidade de conteúdos existentes na disciplina de educação especial. Desta forma, observa-se a relevância da utilização de estratégias inovadoras de ensino como facilitadoras de construção de conhecimentos referentes à disciplina de Educação Especial, dada sua importância no momento atual vivenciado por todos em uma sociedade que busca a inclusão educacional e social. Assim, com a utilização de estratégias inovadoras de ensino tal situação pode ocorrer de modo otimizado, oportunizando uma melhor apreensão e, consequentemente, um melhor uso dessa aprendizagem. 


\subsection{Mapa conceitual como meio para construçáo de conhecimentos}

O mapa conceitual é uma estratégia inovadora de ensino que decorre da teoria de aprendizagem de David Ausubel, psicólogo, que destaca a possibilidade de adquirir conceitos de forma clara e diferenciada como um aspecto essencial na aprendizagem (MOREIRA, 1993). Assim, o mapa conceitual pode ser utilizado como um valioso instrumento pelo professor, pois a construção deste obrigatoriamente perpassa o entendimento acerca do conteúdo proposto.

Ao discorrer sobre esta teoria cognitiva Moreira (1993, p. 19) diz que ela "procura explicar teoricamente o processo de aprendizagem segundo a óptica do cognitivismo. A psicologia da cognição (cognitivismo) procura descrever, em linhas gerais, o que sucede quando o ser humano se situa e organiza no mundo". Assim, os mapas conceituais embasam-se nesta para desenvolver os processos cognitivos que são essenciais para realizar a sua construção.

Sobre os mapas conceituais, Moreira (1993, p. 13), explica seu conceito evidenciando que:

[...] mapas conceituais são diagramas hierárquicos indicando os conceitos $\mathrm{e}$ as relações entre esses conceitos. Esses conceitos procuram refletir a organização dos conceitos de uma disciplina ou parte de uma disciplina, de um livro, de um artigo, de uma experiência laboratorial, da estrutura cognitiva de um indivíduo sobre um dado assunto, de uma obra ou de uma outra fonte ou área de conhecimentos qualquer.

Assim, é possível utilizar mapas conceituais em diversas situações em sala de aula, oportunizando àqueles que os utilizam, construir e relacionar conceitos de forma significativa. Além de servir como um instrumento interessante para o professor agregar às suas estratégias educativas, possibilitando, inclusive, usá-lo em momentos avaliativos. Pois este é um instrumento que pode ser considerado um revelador da aprendizagem do aluno quando trabalhado ao final de um determinado conteúdo.

Em se tratando da avaliação da aprendizagem, o mapa conceitual pode ser um instrumento "simples, que permite logo ao professor saber <onde está o aluno>" (MOREIRA, 1993, p. 58), possibilitando nesse ínterim perceber se o aluno construiu novas ideias, entendeu o conteúdo, soube hierarquizar, diferenciar, estruturar, dentre outras situações os conceitos de um determinado conteúdo, tópico, disciplina.

Enquanto estratégias cognitivas que mediam a construção de conhecimentos, os mapas conceituais possibilitam inúmeros ganhos, uma vez que mobilizam o aluno no planejamento, monitoramento, pensamento, consciência acerca de tomada de decisões, ou seja, exercendo a metacognição. Conforme Pozo, Monereo e Castelló (2004, p. 153) é relevante "ter consciência de alguns dos conhecimentos que manejamos e de alguns dos processos mentais que utilizamos para gerir tais conhecimentos". Por conseguinte, a mediação do professor torna-se salutar nesse cenário. Sobre esse aspecto Vieira (2013, p. 190) descreve que: 
$\mathrm{Na}$ escola contemporânea, o papel do professor torna-se cada vez mais complexo se lhes juntarmos todas as mediações necessárias a implementar. O professor/educador tem de ter conhecimento do meio e do território e usá-lo com propriedade no processo de ensino-aprendizagem.

Sendo assim, fazer diversos tipos de mediação faz parte do papel do professor na contemporaneidade, as mediações necessárias para que ocorra o aprendizado são essenciais. Nesse contexto, o trabalho de mediar os diferentes momentos educativos no chão da escola constitui parte do processo de ensino e consequentemente da aprendizagem dos educandos. Assim, as potencialidades de desenvolvimento dos educandos por meio dos mapas conceituais são indubitáveis, podendo ser agregados ao planejamento dos docentes como mecanismos que favoreçam uma aprendizagem significativa.

\subsection{Aprendizagem baseada em problemas como meio para construçáo de conhecimentos}

A aprendizagem baseada em problemas (ABP) é uma estratégia considerada relevante por seu caráter prático, permitindo que o aluno desenvolva habilidades, tais como: a resolução de problemas que, conforme os objetivos propostos pelo professor podem embasar a futura atuação profissional. Também viabiliza a realização de pesquisas que subsidiem a construção de possíveis soluções e a autonomia dada ao aluno para o desenvolvimento de um problema ou mesmo de um projeto.

Nas palavras de Arão e Chaves (2013) a ABP tem dentre vários objetivos o de estimular os educandos a resolverem problemas de modo autônomo e eficiente, participarem de discussões por meio de um trabalho articulado em equipe, além de possibilitar a construção de proposições que permitirão o surgimento de novas ideias.

A atuação do professor, ou seja, suas ações, valores, desejos etc., estão vinculados à prática educativa. Nesse sentido, o professor em sala de aula deve proporcionar aos alunos meios e mecanismos inovadores que lhe possibilitem uma melhor apreensão dos conteúdos propostos. Ainda nesse sentido, os autores supracitados destacam que a profissão envolve a "capacidade para conceber e implementar novas alternativas, diante da crise e dos problemas da sociedade" (PIMENTA; ANASTASIOU, 2010, p. 196).

Nessa ótica, a ABP no entendimento de Araújo e Sastre (2009, p. 26) “[...] afasta a perspectiva da compreensão de conceitos comuns e a situa na capacidade de desenvolver novos conhecimentos". O autor menciona ainda que um dos benefícios que esse tipo de estratégia proporciona ao acadêmico é o crescimento deste por meio de indagações, sobretudo, por colocar o aluno no centro do processo permitindo que sua proatividade se manifeste de forma protagonizada.

Acerca da ABP é relevante ressaltar ainda que "[...] o ensino baseado em problemas trabalha questões relevantes, atuais, para as quais a sociedade, as 
empresas ou a vida real ainda não encontram solução" além de destacar que o uso desta metodologia de ensino "[...] permite que os grupos escolham os problemas com os quais desejam trabalhar e tentem analisá-los e resolvê-los" (ARAÚJO; SASTRE, 2009, p. 24).

Portanto, a ABP é uma estratégia inovadora de ensino que pode contribuir para o aluno ter autonomia no processo de reflexão, análise, construção e até compreensão de um determinado conceito, baseado nos seus conhecimentos prévios e na pesquisa embasada em aportes teóricos coerentes com a proposta apresentada pelo professor.

\section{MAPA CONCEITUAL E APRENDIZAGEM BASEADA EM PROBLEMAS: UMA EXPERIÊNCIA CONSTRUTIVA}

Com o propósito de aplicar os conhecimentos advindos dos aportes teóricos estudados sobre estratégias inovadoras de ensino neste trabalho, buscou-se desenvolver as estratégias de ensino "Mapa conceitual e Aprendizagem baseada em problemas" com alunos de um curso de Pedagogia de um IES de Imperatriz-MA. Além de desenvolver estratégias inovadoras de ensino com os estudantes, buscouse conhecer as percepções dos estudantes quanto ao uso destas estratégias em sala de aula. Para tanto, foram realizadas três perguntas para os estudantes, sendo as respostas analisadas de forma descritiva.

As atividades vinculadas às estratégias já mencionadas foram desenvolvidas nas aulas da disciplina Educação Especial, no curso de Pedagogia, entre os meses de janeiro a abril de 2016, com 14 alunos, destes 12 (doze) mulheres e dois homens, a faixa etária dos mesmos variou entre 18 a 55 anos.

Referente à disciplina ministrada, sua ementa é bem diversificada permitindo que houvesse um planejamento mais dinâmico e variado com vistas a mediar a aprendizagem dos alunos. Assim a opção por estratégias inovadoras de ensino se fez bastante oportuna, pois estas foram vinculadas e norteadas, além de fundamentadas por metodologias ativas de ensino e de aprendizagem.

Visando atender o objetivo deste estudo que é analisar a percepção de alunos do curso de Pedagogia de uma instituição de Ensino Superior no município de Imperatriz-MA sobre a utilização das estratégias de ensino: mapa conceitual e aprendizagem baseada em problemas, segue a seguir a experiência vivenciada em sala de aula com a utilização destas estratégias inovadoras de ensino.

\subsection{Práticas pedagógicas desenvolvidas}

A estratégia mapa conceitual foi a primeira estratégia desenvolvida neste estudo, assim houve previamente uma explicação breve da mesma por meio de explicação verbal e auxílio de slide contendo exemplos de mapas, pois como enfatizam Monereo; Ignacio e Castello (2004, p. 169): 
A apresentação ou a explicitação de uma estratégia se proporia a favorecer a tomada de consciência por parte do aluno de que determinadas tarefas implicam um planejamento prévio, uma regulação e uma avaliação do processo [...] servem para realizar com êxito as tarefas cognitivas.

Por isso, os alunos foram informados sobre a estratégia, visto que, é possível que alguns já possuíssem conhecimentos prévios a respeito desta e outros não. Houve um momento de explicação sobre a referida estratégia, algumas dúvidas foram sanadas permitindo assim o desenvolvimento da mesma. Desse modo, as formas de construção de cada aluno puderam ser melhor percebidas, facilitando a obtenção de informações e relacionando com a evolução dos acadêmicos.

Para a construção dos mapas conceituais a turma foi dividida em quatro grupos, posteriormente houve o sorteio dos tópicos referentes à temática. Os grupos se reuniram em sala de aula para estudar e definir como procederiam para concretizar a tarefa. O acompanhamento da professora em todos os grupos nesse primeiro momento foi mais específico, já que o conteúdo proposto era novo para os alunos. Assim alguns pontos foram explicados e perguntas foram respondidas com o intuito de proporcionar mais clareza acerca da temática em estudo.

Para o desenvolvimento das atividades foram reservadas três horas-aulas, desmembradas da seguinte forma: uma hora para o trabalho de fundamentação teórica de conceitos relacionados ao conteúdo "Histórico da Educação Especiall"; uma hora para elaboração dos mapas conceituais e na aula seguinte a apresentação visual e oral dos mapas elaborados pelos grupos.

Durante a construção dos mapas conceituais foram usados os seguintes materiais: papel madeira, papel A4 e pinceis marcadores permanentes nas cores, azul e vermelho. Mais uma vez houve a mediação da professora que retomou a explicação sobre a construção dos mapas, mostrando inclusive um exemplo de um já pronto. $\mathrm{O}$ uso de slide foi necessário para demonstrar por meio de imagem a disposição de alguns modelos de mapas conceituais.

A confecção dos mapas ocorreu em sala de aula, com a participação de todos os alunos. Dúvidas em relação à forma, relações que deveriam ser estabelecidas e sobre o uso dos verbos de ligação também surgiram. Assim, houve o acompanhamento da docente com explicações sobre como deveria ser a construção dos mapas, das palavras-chave e trechos que melhor se adequam a cada termo escolhido, assim como a mediação para que no momento da construção os alunos se sentissem mais seguros.

Para finalizar esta estratégia os grupos apresentaram os mapas produzidos, realizando as explicações e as relações que fizeram sobre seus tópicos. Vale ressaltar também que, alguns grupos demonstraram maior desenvoltura no desenvolvimento das explicações de seus mapas, chegando a fazer relações mais aprofundadas acerca do conteúdo proposto.

Quanto ao desenvolvimento da estratégia Aprendizagem baseada em problemas, o planejamento e aplicação dos passos referentes à sua construção ocorreu de modo mais prolongado, visto que, a partir das explicações, momentos 
de estudo e debates, esta permite trabalhar de forma mais autônoma os processos de mediação da aprendizagem aos alunos. Assim, inicialmente houve o estudo da temática "Políticas públicas da educação especial", estruturadas por meio de leituras de textos, socialização, debates e discussões pertinentes ao conteúdo, totalizando cinco horas-aulas. Convêm ressaltar que o conteúdo acima apresentado faz parte da ementa da disciplina e se configura como essencial para o entendimento acerca de mecanismos legais e documentos norteadores da educação especial numa perspectiva inclusiva.

A partir deste embasamento, houve a construção da questão de aprendizagem que se deu de forma articulada entre todos os alunos. Ficando assim definida: "Como as políticas públicas devem buscar mecanismos para efetivar ações em prol de Educação de qualidade?" Logo em seguida os alunos foram solicitados a construírem um texto individual, com o intuito de tentar responder ao questionamento acima explicitado. A próxima etapa foi a junção dos textos. Essa parte da estratégia se deu também por meio de diálogos e discussões entre os componentes dos grupos que em consenso definiram como seria a estrutura textual da etapa de construção coletiva, que conforme orientação do professor teria a estrutura de um artigo científico.

É importante ressaltar que esta estratégia a priori foi vista com muita surpresa por parte dos alunos, inclusive havendo algumas opiniões negativas referentes à eficácia de seu desenvolvimento e sua construção. Situação que pode ser considerada normal, já que diante da apresentação da atividade toda a turma destacou não conhecer tal estratégia de ensino. Todavia, com o desenrolar das atividades, o entusiasmo tomou conta da turma, que se mostrou muito propícia à concretização das atividades.

\subsection{Percepçáo dos estudantes}

Finalizada a construção coletiva do artigo, buscou-se identificar de modo mais aprofundado a percepção dos alunos sobre as estratégias de ensino que foram utilizadas no decorrer da disciplina de educação especial. Assim três questionamentos se fizeram pertinentes para a análise em questão:

Primeira questão: saber a percepção dos alunos sobre o uso em sala de aula do mapa conceitual e da aprendizagem baseada em problemas. Em relação ao mapa conceitual, apesar de eles terem apreciado a proposta, alguns declararam certa insegurança em relação à tarefa pelo fato de ela representar uma novidade em termos de estratégia de ensino.

Alguns estudantes sentiram dificuldade, entretanto, dada a construção dos mapas em cada grupo, boa parte dos alunos destacaram ter alcançado a aprendizagem, compreendido o conteúdo e apesar do desafio, o interesse em concretizar a proposta foi imenso.

Sobre a aprendizagem baseada em problemas a maioria revelou que foi muito inovadora, diferente e desafiadora. Em algumas respostas isso ficou muito nítido. 
Assim seguem alguns trechos dos discursos dos alunos, que foram identificados com a codificação (A1, A2, A3...). "A estratégia aprendizagem baseada em problemas foi gratificante..." (A5); "Me senti desafiada em todo o processo, mas foi muito bom" (A9); "Não conhecia essa estratégia, fiquei confusa, mas depois o aprendizado foi se construindo conforme a conclusão de cada etapa" (A2).

De acordo com Araújo e Sastre (2009) a aprendizagem baseada em problemas instiga os alunos a aprender e buscar relacionar os conhecimentos de diferentes áreas, já que os problemas da vida real não se encontram dissociados de seu contexto, cabe ao aluno a partir das ferramentas disponíveis lidar com as questões propostas e tentar encontrar meios para solucioná-las.

Segunda pergunta: como as estratégias de ensino mapa conceitual e aprendizagem baseada em problemas proporcionaram a construção de conhecimentos? Dentre as respostas houve a seleção das seguintes: "Aprendi a fazer mapas conceituais, isso foi excelente para a minha construção profissional" (A11); "A resolução de problemas faz parte da vida de todos, essa estratégia me proporcionou um olhar mais aprofundado sobre como tratar as problemáticas da sociedade" (A6); Com as estratégias de ensino pude compreender de forma diferenciada conteúdos que tradicionalmente seriam vistos de modo comum" (A14).

Com efeito, a possibilidade de adquirir conhecimentos de modo inovador fica bem evidenciado nos discursos dos alunos. Distanciar-se das metodologias mais tradicionais dependendo do conteúdo é válido e eficiente, pois o propósito fundamental da ação docente é promover a aprendizagem de forma significativa.

Proporcionar uma construção significativa aos futuros profissionais da educação, além de qualificação é de extrema relevância na sociedade atual. Fazer do processo formativo um importante elemento para o desenvolvimento dos indivíduos nesse novo formato social em que as transformações no mundo científico, as tecnologias, enfim, ocorrem de forma dinâmica é papel do professor, assim como oportunizar aprendizagens que serão úteis para o cotidiano laboral (GARCÍA, 1999).

Terceira questão: qual a opinião dos alunos sobre o aproveitamento e aprendizagem das estratégias usadas na disciplina de educação especial. As respostas foram unânimes, todos os alunos afirmaram que obtiveram aprendizados coerentes e que as estratégias se mostraram profícuas na construção de conhecimentos.

É importante, ainda, frisar que o desenvolvimento destas estratégias só foi possível mediante a aceitação por parte dos alunos em realizá-las. Apesar de alguns pontos negativos, a exemplo, a incompreensão da eficácia de uma das estratégias, o resultado final foi imensamente proveitoso, podendo afirmar inclusive que 
estratégias de ensino bem aplicadas são meios excelentes para uma a mediação de aprendizagens significativas ${ }^{3}$.

\section{CONSIDERAÇÓES FINAIS}

As estratégias de ensino são fortes instrumentos de trabalho para auxiliarem os educadores no processo de aprendizagem dos alunos. Levando em consideração que a prática do docente em sala de aula pode ter repercussões motivacionais, é relevante propor atividades cooperativas, individuais e até competitivas (TAPIA; MONTERO, 2004).

Os autores supracitados ressaltam ainda que para motivar os alunos é necessário lançar mão de estratégias que possibilitem motivá-los intrinsecamente. Nesse sentido, proporcionar aos alunos novas construções a partir de instrumentos que promovam a aprendizagem é salutar, de modo que a utilização do mapa conceitual e da aprendizagem baseada em problemas são mecanismos que podem ser usados para essa finalidade.

Assim, diante do exposto, as estratégias anteriormente mencionadas foram utilizadas em sala de aula para mediar a construção de conhecimentos dos acadêmicos do curso de pedagogia de uma IES de Imperatriz-MA. Estes se mostraram interessados em realizar atividades diferenciadas, o que propiciou um bom desenvolvimento das mesmas.

Em relação, ao mapa conceitual, foi notório que o ensino contribuiu para tornar os alunos mais críticos, reflexivos, além de desafiá-los a conceituar, sintetizar e relacionar os conceitos pertinentes. Desse modo, a prática dessa atividade visou à construção consciente de futuras tomadas de decisão na vida social e profissional.

A estratégia de ensino aprendizagem baseada em problemas, possibilitou a participação de toda a turma, apesar de alguns relutarem inicialmente em contribuir. Mas ao perceber o desenrolar desta, ficaram mais seguros para opinar, discutir e construir os textos propostos, de maneira que ao final da atividade foi possível perceber as acepções dos alunos acerca do conteúdo proposto, bem como, ter um embasamento sobre suas construções.

O que ficou mais evidente foi, a possibilidade de motivar os alunos por meio do desenvolvimento destas estratégias de ensino pois, a priori, pensou-se realmente que eles se engajariam para realizá-las. Observou-se que os alunos se motivaram no decorrer do processo de forma aprofundada para que o artigo ficasse a contento para que posteriormente eles pudessem submeter a algum período científico, o que configurou um resultado inesperado, de modo que, por meio destas atividades foi possível construir competências para o desenvolvimento profissional dos estudantes.

3 Processo pelo qual um novo conhecimento ou uma nova informação se relaciona de maneira não arbitrária e substantiva (não literal) à estrutura cognitiva do aprendiz (AUSUBEL, 2003). 
Foi muito gratificante notar que a experiência de ensino aqui descrita, enfoca com clareza as potencialidades de utilização de estratégias de ensino em sala de aula, de forma a atuar como mecanismos de decodificação, cognição, assimilação e interação. É ainda interessante ressaltar que, os alunos passaram a se motivar por se tornar parte desse processo, eles não apenas absorveram as ideias, mas realizaram construções.

Portanto, realizar essa experiência utilizando estratégias inovadoras de ensino, foi extremamente salutar para vislumbrar novas percepções, evidenciar as possibilidades de mediar a aquisição de conhecimentos, bem como, perceber que o planejamento e aplicação de atividades com objetivos bem definidos são eficientes mecanismos para tornar os educandos mais motivados a aprender e aplicar suas construções na vida profissional.

\section{REFERÊNCIAS}

ANASTASIOU, Léa das Graças Camargos; ALVES, Leonir Pessate (orgs.). Processos de Ensinagem na universidade: pressupostos para as estratégias do trabalho em aula. Joinvilie, SC, Editora Univille, 2003, 145 p.

ARÃO, Luis Carlos. CHAVES, Andréa Carla. Estratégias para o Ensino de Fitoterapia por competências: Cadernos de apoio para professores. PUC-Minas. Belo Horizonte: 2013.

ARAÚJO, Ulisses F.; SASTRE, Genoveva (orgs). Aprendizagem baseada em problemas no ensino superior. São Paulo: Summus, 2009.

BRASIL, Conselho Nacional de Educação. Resolução CNE/CP 1, de 18 de Fevereiro de 2002. Disponível em: < http://portal.mec.gov.br/cne/arquivos/pdf/rcp01_02.pdf>. Acesso em 14/ 05 / 2016 às 22:45.

BORDENAVE, Juan Díaz; PEREIRA, Adair Martins. Estratégias de ensino e aprendizagem. Editora vozes. Petrópolis, 2000.

. Estratégias de Ensino e aprendizagem. Editora vozes. Petrópolis, 2008.

GARCÍA, Carlos Marcelo. Formação de professores: para uma mudança educativa. Tradutora: Isabel Narciso. Porto- Portugal, Porto Editora, 1999.

GIL, Antônio Carlos. Métodos e técnicas de pesquisa social. 6 ed. São Paulo: Atlas, 2008.

Didática do Ensino Superior. 1 ed. - 7 reimpr. São Paulo. Atlas. 2012.

MARTÍN, Elena; SOLÉ, Isabel; A aprendizagem significativa e a teoria da assimilação. IN: COLL, César (org). Desenvolvimento psicológico e educação. Tradução Fátima Murad. - 2. Ed. - Porto Alegre: Artmed, 2004.

MASETTO, Marcos Tarciso. Competência pedagógica do professor universitário. São Paulo. Summus, 2003. 
MONEREO, Carles; IGNACIO, Pozo; CASTELLÓ, Montserrat. O ensino de estratégias de aprendizagem no contexto escolar. IN: COLL, César (org).

Desenvolvimento psicológico e educação. Tradução Fátima Murad. - 2. Ed. - Porto Alegre: Artmed, 2004.

MOREIRA, Marco antónio; BUCHWEITZ, Bernardo. Novas estratégias de ensino e aprendizagem: os mapas conceptuais e o Vê epistemológico. 1 edição. Plátano-Edições Técnicas. Lisboa, 1993.

NOGARO, Arnaldo; DALMINA, Rute Rosangela. Contribuição da aprendizagem mediada para a formação de professores. Interfaces da educação. v. 5. n. 15. Paranaíba, 2014.

PERRENOUD, P. Avaliação: da excelência à regulação das aprendizagens - entre duas lógicas. Porto Alegre: Artmed, 1999.

PIMENTA, Selma Garrido; ANASTASIOU, Léa das Graças Camargo. Docência no ensino superior. 4. ed. São Paulo: Cortez. 2010.

POZO, Ignacio Juan; MONEREO, Carles; CASTELLÓ, Montserrat. O uso estratégico do conhecimento. IN: COLL, César (org). Desenvolvimento psicológico e educação. Tradução Fátima Murad. - 2. Ed. - Porto Alegre: Artmed, 2004.

SEVERINO, Antônio Joaquim. Metodologia do Trabalho Científico. 23 ed. São Paulo:Cortez, 2007.

TAPIA, Jesús Alonso; MONTERO, Ignacio. Orientação Motivacional e estrátegias motivadoras na aprendizagem escolar. IN: COLL, César (org). Desenvolvimento psicológico e educação. Tradução Fátima Murad. - 2. Ed. - Porto Alegre: Artmed, 2004.

VIEIRA, Ana Maria. Da educação e da mediação de tensões sociais, indisciplina e violência na escola. Caderno Pedagógico. V 10 n. 2. Lajeado, 2013. 